\title{
44585 - ACUTE, PROLONGED ENHANCEMENT OF NMDA RECEPTOR RESPONSES BY REMIFENTANIL IN RAT DORSAL HORN NEURONS
}

Disclosure: Grants/research support - University of Toronto, Dean's Fund New Investigator Award, 2006

\author{
Daisy Joo, The Hospital for Sick Children, Toronto, ON, Canada; \\ Min Zhao, The Hospital for Sick Children; \\ Rasa Venclovas, The Hospital for Sick Children;
}

INTRODUCTION: Opioid-induced hyperalgesia (OIH) occurs after a brief $(<60-\mathrm{min})$ exposure to remifentanil ${ }^{1}$ and contributes to an increase in postoperative pain. ${ }^{2}$ Pain signaling in the CNS is mediated by excitatory glutamatergic neurotransmission involving the activation of NMDA receptors expressed on dorsal horn (DH) neurons. Increases in NMDA receptor function have been shown to occur after chronic morphine exposure. ${ }^{3}$ This study was undertaken to determine whether remifentanil exposure causes a rapid and prolonged increase in NMDA receptor function that correlates with the development of remifentanil-induced hyperalgesia.

METHODS: After approval by the institutional animal services committee, fetal DH horn neurons were obtained, plated and grown in primary culture for 14 to 21 days.

Electrophysiological studies were then undertaken in a subpopulation of small, tonic firing DH neurons that were previously shown to have increased NMDA receptor current after chronic morphine exposure. ${ }^{2}$ Voltage clamped, whole cell NMDA-evoked current were recorded before, during, and after a 60-min perfusion with remifentanil 0 (control), 1, 4, and $10 \mathrm{nM}$. Peak NMDA current amplitudes normalized to cell capacitance and to baseline were measured in control and remifentanil exposed neurons.

RESULTS: Compared to control neurons, the normalized NMDA-evoked peak current amplitudes recorded in selected DH neurons were increased $(\mathrm{p}<0.01)$, within the first 15 min (percent difference, $+18.0 \%$ ), up to $+41.5 \%$ during the 60 -min exposure to remifentanil $4 \mathrm{nM}$. The increase in the NMDA-evoked current was greatest $(+56.9 \%$ above control current) upon remifentanil washout and remained elevated for the duration of the 30-min washout period. There were insignificant increases in NMDA receptor current after remifentanil $1 \mathrm{nM}$ exposure. However, with remifentanil $10 \mathrm{nM}$, no NMDA receptor enhancement was seen during the remifentanil perfusion, but an increase in the peak amplitude of the NMDA current $+40.9 \%$ above control levels occurred upon washout.

DISCUSSION: Therefore, an increase in NMDA receptor function occurs rapidly during remifentanil exposure with a time course that parallels the clinical development of remifentanil hyperalgesia. Further enhancement of the NMDA-evoked current seen on washout of remifentanil may account for increases in pain on remifentanil withdrawal. The greatest increase in NMDA receptor function occurred with remifentanil $4 \mathrm{nM}$ which corresponds to levels achieved with clinical infusion rates of $0.1-0.15 \mu \mathrm{g} / \mathrm{kg} / \mathrm{min}$. The short onset, prolonged effect and dose dependence of the remifentanil-induced NMDA receptor enhancement in sensory spinal neurons suggest that these cellular changes may contribute to the development of remifentanil-induced hyperalgesia. 
REFERENCES: 1. Pain 2003 106: 49-57 and 91-99. 2. Anesthesiol 2000 93: 409-417. 3. Anesthesiol 2006 104: 815-825.



